\title{
Long-term follow-up of retrograde colonic irrigation for defaecation disturbances
}

\author{
M. P. Gosselink*, M. Darby*, D. D. E. Zimmerman*, A. A. A. Smits*, I. van Kessel*, W. C. Hop†, \\ J. W. Briel* and W. R. Schouten* \\ * Colorectal Research Group of the Department of Surgery, and +Department of Epidemiology and Biostatistics, Erasmus Medical Centre, Rotterdam, \\ the Netherlands
}

Received 15 June 2004; accepted 22 June 2004

\begin{abstract}
Objective Irrigation of the distal part of the large bowel is a nonsurgical alternative for patients with defaecation disturbances. In our institution, all patients with defaecation disturbances, not responding to medical treatment and biofeedback therapy, were offered retrograde colonic irrigation (RCI). This study is aimed at evaluating the long-term feasibility and outcome of RCI.

Methods Between 1989 and 2001, a consecutive series of 267 patients was offered RCI. All patients received instructions about RCI by one of our enterostomal therapists. Twenty-eight patients were lost to follow-up. A detailed questionnaire was sent by mail to 239 patients. The total response rate was 79\% (190 patients). Based on the returned questionnaires it became clear that 21 (11\%) patients never started RCI. The long-term feasibility and outcome of RCI was therefore assessed in the remaining group of 169 patients. Thirty-two patients were admitted with soiling, 71 patients with faecal incontinence, 37 patients with obstructed defaecation and 29 had defaecation disturbances after low anterior resection or pouch surgery.
\end{abstract}

Results According to the returned questionnaires, RCI was considered effective by 91 (54\%) patients. Among patients with soling and faecal incontinence, RCI was found to be effective in, respectively, 47 and $41 \%$ of the subjects. Despite of the reported effectiveness, $10(67 \%)$ patients with soiling and $5(17 \%)$ patients with faecal incontinence decided to stop. Among patients with obstructed defaecation and those with defaecation disturbances after low anterior resection or pouch surgery the effectiveness of RCI was found to be 65 and 79\%, respectively. None of these patients ceased their therapy. The overall success-rate of long-term RCI was therefore $45 \%$.

Conclusions Long-term RCI is beneficial for $45 \%$ of patients with defaecation disturbances. In the group of patients who considered RCI effective and beneficial, discontinuation of therapy was only observed among those with soiling and faecal incontinence.

Keywords Retrograde colonic irrigation, faecal incontinence, soiling, obstructed defaecation, low anterior resection, pouch surgery

\section{Introduction}

Defaecation disturbances are disabling conditions and might affect the quality of life $[1,2]$. According to some authors irrigation of the distal part of the large bowel is beneficial for patients with problems such as faecal soiling, faecal incontinence or obstructed defaecation

Read at the meeting of the Netherlands Association of Surgery $(\mathrm{NVVH})$, Veldhoven, the Netherlands, May 15-16, 2003.

Correspondence to: Dr W. Rudolph Schouten, Department of Surgery, HIO43 Erasmus Medical Centre, Rotterdam (Dijkzigt), Dr Molewaterplein 40, 3015 GD Rotterdam, the Netherlands.

E-mail: w.r.schouten@erasmusmc.nl
[3-5]. Colostomy washout has been used for several decades [6-11]. This technique has been proven to be safe and provides the opportunity to avoid wearing a colostomy bag. Many patients prefer colostomy washout to natural evacuation. In 1989, Iwama et al. [12] introduced the rectal application of a conventional colostomy irrigation set in order to washout the distal part of the colon in 10 patients, who complained of frequent urge to defaecate and impairment of bowel control after low anterior resection. In all these patients, the frequent urge to defaecate disappeared.

In our institution retrograde colonic irrigation has been offered to patients with defaecation disturbances, 
not responding to medical treatment and biofeedback since 1989. In an earlier report we showed that RCI was beneficial for $79 \%$ of patients with soiling and $38 \%$ of patients with faecal incontinence, however, the median duration of the treatment was 18 months [4].

The aim of the present study is to evaluate the longterm feasibility and outcome of RCI in patients with defaecation disturbances.

\section{Materials and methods}

Between 1989 and 2001, a consecutive series of 267 patients with disturbed continence or obstructed defaecation, not responding to medical treatment and biofeedback, were offered retrograde colonic irrigation (RCI) on an ambulatory basis. All patients were instructed by one of our enterostomal therapists. Hospital records and outpatient clinic data were analysed. Twentyeight patients were lost to follow-up. Fifteen of them died during follow-up and 13 patients could not be contacted as they had moved abroad and their new address was not available. A detailed questionnaire was sent by mail to 239 patients. The questionnaire included questions about the method of retrograde colonic irrigation, the effectiveness of RCI in releasing the patients from their original complaints, continuation (or discontinuation) of treatment, procedure related problems and patient satisfaction. Procedure related problems were abdominal discomfort, too time consuming, anal pain, loss of instilled water during the day and technical problems. Technical problems included problems with instillation of the water, problems evacuating the instilled water and rapid loss of instilled water before achieving adequate washout. The total response rate was $79 \%$ (190 patients). Based on the returned questionnaires it became clear that after the initial instruction, 21 (11\%) patients did not start with RCI. Eleven patients decided not to start with RCI since their original complaints disappeared spontaneously. Ten patients considered RCI as embarrassing and inconvenient. The long-term feasibility and outcome of RCI was therefore assessed in the remaining group of 169 patients. Thirty-two patients were admitted with faecal soiling, 71 patients with faecal incontinence, 37 patients with obstructed defaecation and 29 had defaecation disturbances after low anterior resection or pouch surgery (Table 1).

For the assessment and grading of faecal incontinence and soiling the classification according to Parks [13] was used. Obstructed defaecation was defined according to a scoring system based on the following five symptoms: excessive straining during defaecation, sensation of incomplete evacuation, manual assistance, sense of fullness and a defaecation frequency of less than three times
Table I Patient characteristics.

\begin{tabular}{lcrll}
\hline Indication & $\begin{array}{l}\text { Number of } \\
\text { responders }\end{array}$ & Males & $\begin{array}{l}\text { Median age } \\
\text { (years) }\end{array}$ & $\begin{array}{l}\text { Range } \\
\text { (year.) }\end{array}$ \\
\hline Soiling & 32 & 28 & 47 & $17-65$ \\
Incontinence & 71 & 21 & 57 & $20-87$ \\
$\begin{array}{l}\text { Obstructed } \\
\begin{array}{l}\text { Defaecation } \\
\text { Defaecation } \\
\text { disturbances }\end{array}\end{array}$ & 37 & 5 & 54 & $20-68$ \\
$\begin{array}{l}\text { after LAR or } \\
\text { Pouch Surgery }\end{array}$ & 29 & 14 & 53 & $25-81$ \\
Total & 169 & 68 & 52 & $17-87$ \\
\hline
\end{tabular}

per week [14]. RCI was only offered to patients with obstructed defaecation in whom colonic transit time was normal. Eleven patients with persistent symptoms of obstructed defaecation after adequate correction of their rectocele and 26 patients with obstructed defaecation without a significant rectocele were offered RCI. The last group consisted of 16 patients with a high stool frequency after low anterior resection, 8 patients with nocturnal incontinence after ileo-anal anastomosis and 2 patients with constipation after colo-anal J-pouch anastomosis.

Proportions were analysed by $\chi^{2}$ test or Fisher's exact test when appropriate. Discontinuation of RCI along time was estimated using the Kaplan-Meier life table method and compared between groups with the log-rank test. $P<0.05$ (two-tailed) was considered the limit of significance. This study on patients had the approval of The Medical Ethical Committee of the Erasmus Medical Centre.

\section{Method of retrograde colonic irrigation}

All patients received both verbal and written instructions about colonic irrigation by one of our enterostomal therapists. A conventional colostomy irrigation set was used. The device consisted of an irrigation bag, a tube and a cone-tip (Biotrol Iryflex, B. Braun Medical B.V., Oss, Netherlands) (Fig. 1). Patients were instructed to hang the irrigation bag at shoulder height or one meter above the toilet seat. The advised volume of tap water varied between 500 and $1000 \mathrm{ml}$. The temperature of the water, used for the washout, had to be approximately 37 degrees centigrade. Cold water had to be avoided since instillation of a volume of cold water might lead to collapse or abdominal cramp. To prevent nausea, the patient was advised to perform the washout at least $2 \mathrm{~h}$ after a meal. The patient was instructed to irrigate the feeding tube prior to introduction of the lubricated cone- 


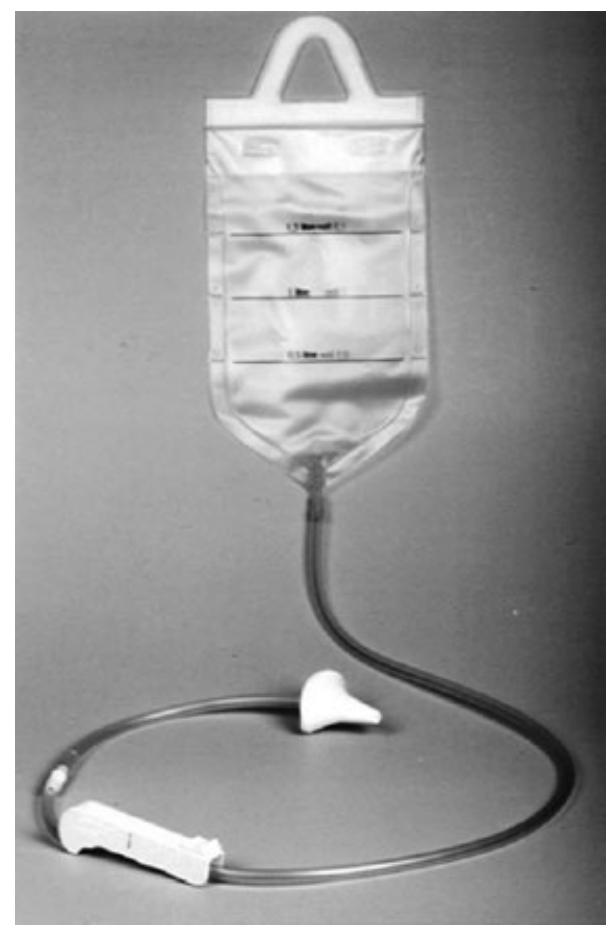

Figure I Irrigation bag with the cone tip at the end of the tube.

tip into the anal canal in order to avoid installation of air in the colon. The patient was instructed to wait until the urge to defaecate was experienced before taking out the cone-tip. After removal of the cone-tip, evacuation of the irrigation fluid could take place.

\section{Results}

The long-term feasibility and outcome of RCI was assessed in the remaining group of 169 patients. The responders were similar as the nonresponders regarding gender, age or underlying defaecation disturbances. The median duration of the time interval between the start of the RCI and the mailing was 56 months (range: 8154 months). RCI was reported to be effective and beneficial by 91 patients $(54 \%)$. Of the total group, 93 patients reported to have ceased RCI after variable periods. All 78 patients in whom RCI was not effective and 15 patients who encountered benefit of RCI, stopped with their irrigation. The overall success-rate of longterm RCI was therefore $45 \%$. Figure 2 shows cumulative discontinuation rates of the total group. These discontinuation rates were not affected by age or gender.

Among patients with soiling and faecal incontinence, RCI was found to be effective in, respectively, 47 and $41 \%$ of the subjects. Despite of the encountered effectiveness, $10(67 \%)$ patients with soiling and $5(17 \%)$ patients with faecal incontinence had decided to discon-

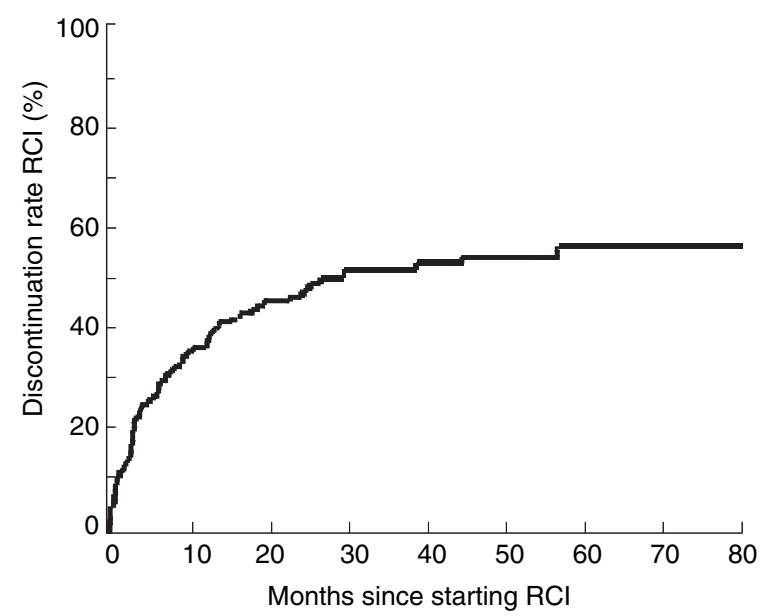

Figure 2 Cumulative discontinuation rates of retrograde colonic irrigation.

tinue their therapy. Patients with soiling had stopped because of the time consuming aspect of RCI and irrigation related problems. The patients with incontinence had stopped RCI because of irrigation related problems and loss of irrigation fluid during the day. Among patients with obstructed defaecation and those with defaecation disturbances after low anterior resection or pouch surgery the encountered effectiveness of RCI was found to be 65 and 79\%, respectively. None of these patients had ceased the irrigation. The Kaplan-Meier curves show that the discontinuation rate among patients with soiling and faecal incontinence is significantly higher than in the two other groups (all $P<0.05$, Fig. 3).

Among the patients who continued RCI, the irrigation frequency varied between once per four days and five

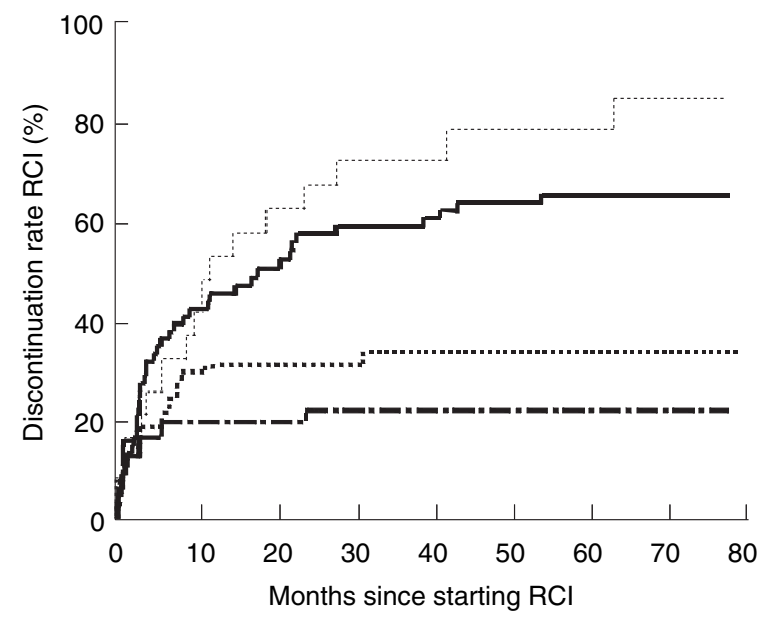

Figure 3 Retrograde colonic irrigation discontinuation rate according to indication. - - - - soiling; —_ incontinence; .......... obstructed defaecation; -..... after LAR or pouch surgery. 


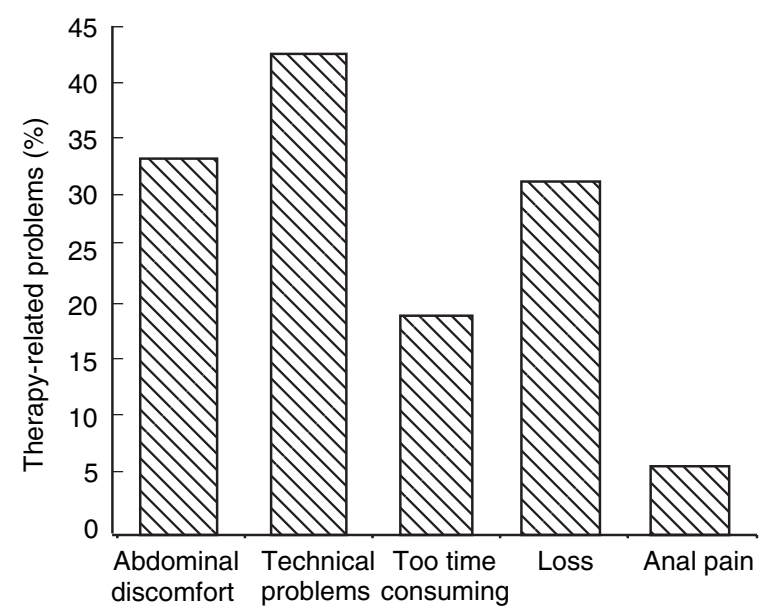

Figure 4 Problems mentioned in 76 patients who still performed retrograde colonic irrigation.

times per day (median frequency one time per day. The median volume of tap water was $1000 \mathrm{ml}$ (range: 500$3000 \mathrm{ml}$ ). The median duration of the RCI was $30 \mathrm{~min}$ (range: 10-115). Most of the patients (83\%) found the morning to be the most appropriate time for irrigation. One out of three patients used medication in order to facilitate their defaecation.

Seventy-four percent of the 76 patients who still performed RCI on a regular basis, indicated to experience irrigation-related problems. The number of these problems varied from one to three. Technical problems, abdominal cramping and loss of irrigation fluid during the day were most frequently reported as therapy related technical problems (Fig. 4).

Despite the high number of RCI-related problems mentioned by the patients still performing RCI, $86 \%$ of them considered RCI as beneficial improving their quality of their lives.

\section{Discussion}

Data regarding the efficacy of RCI in patients with defaecation disturbances are scarce. As far as we know only five studies have been conducted in order to evaluate this treatment modality $[3-5,12,15]$. In these five studies, however, only a small number of patients have been included. Furthermore, the median duration of follow-up was short. The present study is the first one assessing long-term follow-up of RCI in a large consecutive series of patients with defaecation disturbances.

The reported efficacy of RCI was higher among patients with obstructed defaecation and those with defaecation disturbances after low anterior resection or pouch surgery than in patients with soiling or faecal incontinence. These findings are in contradiction with those reported by other workers. Krogh et al. [5] observed significant improvement in bowel function among $42 \%$ of patients with faecal incontinence. A similar improvement was found in only $18 \%$ of their patients with constipation or obstructed defaecation. Christensen et al. [3] offered RCI to 21 patients with constipation or faecal incontinence due to spinal cord injury, spina bifida or cerebral palsy. In the patients with faecal incontinence as a predominant symptom the outcome was successful in $73 \%$. Among those with constipation or obstructed defaecation, RCI was successful in $40 \%$ of the subjects. It has been shown that administration of more than $250 \mathrm{ml}$ water through a colostomy generates colonic mass movements [16]. According to Christenssen et al. [15] the lower efficacy of RCI in constipation might be due to the fact that the large bowel wall of constipated patients is less prone to respond to stimuli. In our opinion this is only the case in slow transit constipation. Patients with this syndrome were not included in the present study. RCI was only offered to patients with obstructed defaecation in whom colonic transit time was normal.

The lack of effect was the most important reason for our patients to cease their therapy. Despite reported effectiveness, $34 \%$ of the patients with soiling or faecal incontinence, stopped with RCI. The overall discontinuation rate in the present study is therefore $55 \%$. Christensen et al. [15] observed a discontinuation rate of $45 \%$.

In our institution all patients with faecal incontinence, not responding to medical treatment and biofeedback therapy, are offered RCI. The discontinuation among patients with faecal incontinence in whom RCI was effective might be explained by the fact that they probably prefer surgical therapy rather than life-long irrigation of their colon. Many patients with soiling also stopped with RCI despite its effectiveness. Their decision to stop was mainly based on the time consuming aspect of the irrigation and the loss of irrigation during the day. Coping with these problems must counterbalance with the consequences of soiling. None of the patients with obstructed defaecation and those with defaecation disturbances after low anterior resection or pouch surgery ceased their therapy if they considered RCI effective. Despite irrigation related problems, they all continued the irrigation. The prospect of a permanent stoma as the only option left might contribute to the high continuation rate in these patients.

Irrigation requires considerable self-motivation and consumes valuable time. Patients are told that complete and predictable bowel control is usually not immediate. During the first month after starting RCI, the irrigation procedure is determined by trial and error with individu- 
alized frequencies of administration and volume of water used. During this initial period, instructions from an experienced nurse with a special interest in this field are very important.

The exact mechanism behind colonic irrigation is still not known. The effect of water administration is in part due to a simple mechanical wash-out effect. It has also been suggested that the administration of water generates colonic mass movements [16]. A few years ago, it has been shown that polyethylene glycol, glycine, bisacodyl and glyceryl trinitrate solutions enhance colonic emptying during irrigation [17].

Some authors advocate antegrade colonic irrigation through an appendicostomy, a tapered ileum or a continent colonic conduit as an attractive alternative for patients with defaecation disturbances [18-21]. O'Bichere et al. [17] have shown that colonic emptying is more efficient with antegrade than retrograde irrigation. One plausible explanation for this greater efficiency of the antegrade approach is that it is directed from the right to the left colon along with normal mass movement waves, ensuring efficient expulsion of stool. This finding has been confirmed recently by Christensen et al. $[15,22]$. These authors used a scintigraphic technique in order to assess the efficacy of both antegrade and retrograde irrigation. Antegrade irrigation resulted in complete emptying of the recto-sigmoid, descending colon and transverse colon, even in patients with severe constipation. The effect of retrograde irrigation was significantly lower, especially in patients with severe constipation. Despite the higher efficacy of antegrade irrigation, we still prefer retrograde irrigation as the first treatment of choice, since it is minimally invasive, easy to learn, safe with only minor side-effects. In our opinion antegrade irrigation should be reserved for those patients in whom retrograde irrigation fails.

\section{References}

1 Rockwood TH, Church JM, Fleshman JW et al. Fecal Incontinence Quality of Life Scale: quality of life instrument for patients with fecal incontinence. Dis Colon Rectum 2000; 43: 9-16.

2 Glia A, Lindberg G, Nilsson LH et al. Clinical value of symptom assessment in patients with constipation. Dis Colon Rectum 1999; 42: 1401-8.

3 Christensen P, Kvitzau B, Krogh K et al. Neurogenic colorectal dysfunction - use of new antegrade and retrograde colonic wash-out methods. Spinal Cord 2000; 38: 255-61.
4 Briel JW, Schouten WR, Vlot EA et al. Clinical value of colonic irrigation in patients with continence disturbances. Dis Colon Rectum 1997; 40: 802-5.

5 Krogh K, Kvitzau B, Jorgensen TM et al. [Treatment of anal incontinence and constipation with transanal irrigation]. Ugeskr Laeger 1999; 161: 253-6.

6 MacLeod JH. Colostomy irrigation - a transatlantic controversy. Dis Colon Rectum 1972; 15: 357-60.

7 Terranova O, Sandei F, Rebuffat C et al. Irrigation vs. natural evacuation of left colostomy: a comparative study of 340 patients. Dis Colon Rectum 1979; 22: 31-4.

8 Williams NS, Johnston D. Prospective controlled trial comparing colostomy irrigation with 'spontaneous-action' method. Br Med J 1980; 281: 107-9.

9 Doran J, Hardcastle JD. A controlled trial of colostomy management by natural evacuation, irrigation and foam enema. Br J Surg 1981; 68: 731-3.

10 Bail JP, Juglard G, Framery D et al. Value of colonic irrigation. Long-term followed-up in 432 colostomized patients. Presse Med 1994; 23: 1651-4.

11 Leong AF, Yunos AB. Stoma management in a tropical country: colostomy irrigation versus natural evacuation. Ostomy Wound Manage 1999; 45: 52-6.

12 Iwama T, Imajo M, Yaegashi K et al. Self washout method for defecational complaints following low anterior rectal resection. Jpn J Surg 1989; 19: 251-3.

13 Parks AG. Anorectal incontinence. Royal Society of Medicine, Section of Proctology; Meeting 27 November 1974. President's Address. Proc R Soc Med 1975; 68: 681-90.

14 Thompson WG, Heaton KW. Functional bowel disorders in apparently healthy people. Gastroenterology 1980; 79: 283-8.

15 Christensen P, Olsen N, Krogh K et al. Scintigraphic assessment of retrograde colonic washout in fecal incontinence and constipation. Dis Colon Rectum 2003; 46: 68-76.

16 Gattuso JM, Kamm MA, Myers C et al. Effect of different infusion regimens on colonic motility and efficacy of colostomy irrigation. Br J Surg 1996; 83: 1459-62.

17 O'Bichere A, Sibbons P, Dore C et al. Experimental study of faecal continence and colostomy irrigation. Br J Surg 2000; 87: 902-8.

18 Malone PS, Ransley PG, Kiely EM. Preliminary report: the antegrade continence enema. Lancet 1990; 336: 1217-8.

19 Krogh K, Laurberg S. Malone antegrade continence enema for faecal incontinence and constipation in adults. Br J Surg 1998; 85: 974-7.

20 Yerkes EB, Cain MP, King S et al. The Malone antegrade continence enema procedure: quality of life and family perspective. J Urol 2003; 169: 320-3.

21 Williams NS, Hughes SF, Stuchfield B. Continent colonic conduit for rectal evacuation in severe constipation. Lancet 1994; 343: 1321-4.

22 Christensen $\mathrm{P}$, Olsen N, Krogh K et al. Scintigraphic assessment of antegrade colonic irrigation through an appendicostomy or a neoappendicostomy. Br J Surg 2002; 89: 1275-80. 